\title{
Sensitivity analysys and potential evaluation using building thermal mass combined with DSM strategies
}

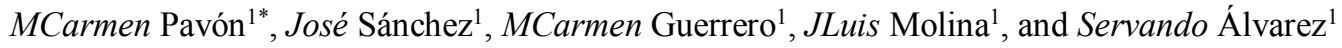 \\ ${ }^{1}$ Grupo de Termotecnia, Universidad de Sevilla, Escuela de Ingenieros Camino de los Descubrimientos s/n. 41092, Seville, Spain.
}

\begin{abstract}
The objective of the work is to develop an algorithm that automatically manages the activation of the heat pump in response to the most appropriate strategies according to the pricing and operating conditions. It is interesting to see if a balance can be reached between the cost savings, the increase in energy consumed, the thermal comfort of the occupants and the contribution to the reduction of the peak loads. The study shows different results and conclusions, highlighting the important influence of various factors on the results obtained, such as user behavior, constructive quality of the building and electric pricing. Connection with a future renewable production can maximize the economic savings; it is interesting the use of buildings as thermal storage of unused photovoltaic surplus. Finally, the possibility of combining these measures with electrical storage and with the possible arbitration linked to renewable production.
\end{abstract}

\section{Introduction}

Around $40 \%$ of the energy consumed is due to buildings, and is responsible for $36 \%$ of greenhouse gas emissions [1]. Therefore, the potential for energy savings is important in this sector, buildings can become one of the main battle points in the fight for a better use of energy and against Climate Change. In addition, in this era of uncertainty regarding energy planning, consumer demand has emerged as a central figure, since it can be seen as a way to balance the supply and demand of electricity by giving a system flexibility, whose responsibility does not fall only in the generation infrastructure.

Faced with this situation, the concept of Demand Side Management (DSM) [2] appears, proposed as a portfolio of measures to improve the energy system on the consumption side in order to modify the profile of customer demand. In the study in question, the analysis will focus mainly on Response to Demand, whose objectives can be summarized in trying to flatten the demand curve by the consumer, reducing loads in those peak hours; so that the client sees it as a potential economic savings and the supplier also, when reaching a generation a little more stable.

An efficient management of building energy is essential for reducing energy demands and greenhouse gas emissions.

\section{Description of studied}

This paper presents the analysis studies of the potential for improvement of Demand Management measures related to the operation of equipment, variation of the set-point temperatures and night ventilation strategies; that is, pre-heating and pre-cooling with or without night ventilation. These measures have as differential elements that the effect is mainly based on the use thermal mass buildings, inertia, and the potential for improvement due to the use is analysed as after rehabilitation or alternative to rehabilitation.

The work consists in the analysis of two real buildings, mainly, located on La Graciosa Island (Las Palmas), complemented by three more buildings located in different areas of the Spanish geography, Malaga, Seville and Madrid. It has been taken into account for the previous buildings different analysis scenarios, from a starting building, which corresponds to the original in each case, to a rehabilitated building. Unified to the existence of two different users, with data of electric pricing within a daily market and taking advantage of the flexibility of heat pumps that can be used depending on the conditions of the grid. In addition, in the definition of the best strategy of operation of the claims manager, an intelligent control is incorporated, which every day can determine which alternative is the most appropriate.

\section{Methodology}

The proposed methodology allows analysing the energy conservation and / or economic savings potential of demand management measures linked to the use of the thermal mass of the building as an energy storage system.

The study methodology consists of five main blocks, as shown in Fig. 1, detailed in the following subsections.

- Building Models: Five existing buildings, which have been visited, and has allowed making the detailed models of each of them, in section 3.1 you can see all the information.

\footnotetext{
* Corresponding author: maricarpavon@ hotmail.com
} 
- User behavior: In order to determine the behavior of users, surveys have been carried out, to know how they operate and their usual schedules of occupation and use, in section 3.2 each of the characteristics of the users studied is defined.

- Climate: The houses have been chosen in different climatic zones of Spain. In block 3.3 each one of the zones is detailed as well as its connection with a potential future of the proposed methodology.

- Electricity prices: After analyzing the Spanish electricity market, the most used tariff has been taken, even so in section 3.4 its properties are specified, as well as other tariffs that have also been taken into account in the analysis of influential factors.

- Decision Maker: Three strategies are mainly studied, focusing on air conditioning, 2 of preconditioning for heating and cooling stations, and one of making use of the outdoor night temperature in summer. In section 3.5, the algorithm followed by management, as well as the strategies, are explained in detail.

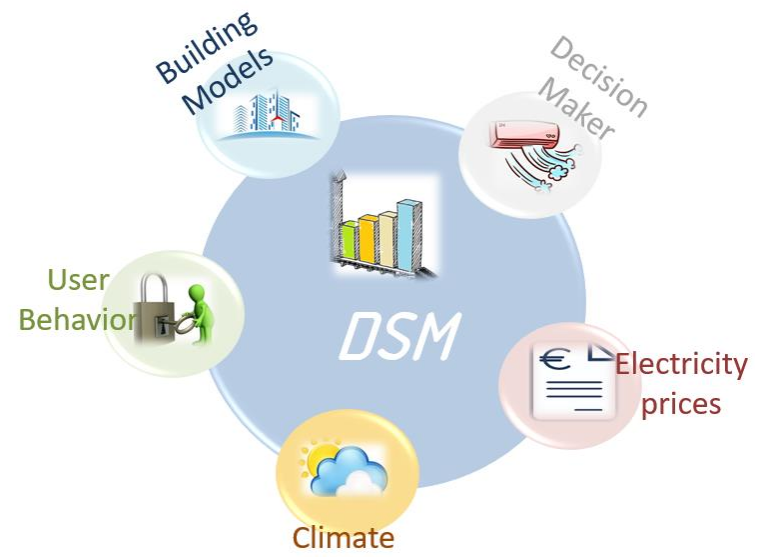

Fig. 1. Scheme of methodology.

\subsection{Building Models}

For the analysis of the thermal behavior and the energetic characterization of the buildings under study, the modelling of the same is carried out.

Building models have been developed with an accurate consideration of the geometry, materials, orientation, exposed surfaces of ceilings, walls, and floors is available. The building models were developed in the detailed Unified LIDER-CALENER software tool (HULC by its Spanish acronym) [3], which is the official building energy certification tool in the country. The real constructive solutions were used.

The reason for using this software is twofold: first, this tool follows a transient and hourly base assessment that has been validated via the Bestest [4], it has been used to obtain the Building Energy Performance Certificate of hundreds of thousands of buildings in Spain, and it has also been used by many studies in the recent literature. Second, this tool was developed within the research group of the authors of the present work, which allowed making certain modifications to be able to carry out the present study.
The sample of studied houses has been chosen within the framework of the GRACIOSA research project. Below are the homes studied, Table 1, as well as the identifier associated with each of them, together with a concise description.

Regarding the facilities, in general, all households have an ACS installation with an electric boiler and a heat pump for air conditioning. All the houses have air conditioning only the living room of the same, however, in this study it is contemplated that there is another system of centralized electric heat pump that conditions the rest of the house, except the bathrooms, the kitchen and the hallway.

After the analysis of the constructive solutions of the initial situation, it can be seen that the houses have generally bad construction qualities, for this reason an analysis is proposed for the improvement of the different dwellings in relation to the thickness of the insulation of the walls, sealing and thermal bridges.

In the first place, the improvement of the envelope is carried out, with the optimization of the insulation thickness, both in walls and facades and floors. This improvement has been made taking into account two different criteria, but at the same time complementary, as recommended by the CTE [5] and analysing the savings achieved in heating, but without forgetting a considerable penalty in the demand for refrigeration. The second measure is to reduce the ACHeq by half, so that the tightness of the holes increases. This measure implies reducing the infiltration of the home more than half of its value. Finally, the last measure taken is to reduce the effect of thermal bridges to $0.1 \mathrm{~W} / \mathrm{m} * \mathrm{~K}$.

Applying this procedure to each of the buildings presented above, the following evolution is carried out, shown in table 2, with respect to the savings that can be achieved, simply with the rehabilitation of energy.

Table 2. Percentages savings with energy rehabilitation.

\begin{tabular}{|c|c|c|}
\hline \multirow{2}{*}{ Building } & \multicolumn{2}{|c|}{ Percentage savings (\%) } \\
\cline { 2 - 3 } & Heating & Total \\
\hline $\mathbf{1}$ & 68.6 & 26.1 \\
\hline $\mathbf{2}$ & 53.3 & 20.7 \\
\hline $\mathbf{3}$ & 15.2 & 7.2 \\
\hline $\mathbf{4}$ & 50.2 & 16.7 \\
\hline $\mathbf{5}$ & 54.5 & 18.1 \\
\hline
\end{tabular}

\subsection{User Behavior}

The present energy system in which energy is generated centrally, on the one hand, and consumed by individual users on the other, offers a framework in which users can play a major role in producing considerable energy savings. 
Several studies have shown that consumers have information about their behavior, reducing up to $14 \%$ [6, 7]. Therefore, it can be determined that the role of the user is a very active in the energy system, not only as a consumer but also as a manager.

In the study in question, two types of daily uses of housing have been defined, an aspect that affects internal sources, in terms of occupation, lighting and equipment; as to ventilation. Moreover, of course to the control system of the conditioning equipment. Ventilation has been considered constant during all hours with occupation and equal to $0.63 \mathrm{ren} / \mathrm{h}$.

However, the distinction between different users appears linked to the hours of operation of the conditioning system. The main differences appear in the treatment of the weekend with respect to the rest and the operation in the different stations. In summer, free oscillation is adopted at night and when there is no presence in the house, and a set temperature of $25^{\circ} \mathrm{C}$ when it is ocupated. In winter, the temperature is in free oscillation at night and when there is no presence in the house, and $20^{\circ} \mathrm{C}$ when there is.

Table 3. User Type.

\begin{tabular}{|c|c|}
\hline User Type & Description \\
\hline User 1 (U1) & Labor-Holiday Day \\
\hline User 2 (U2) & Summer- Winter \\
\hline
\end{tabular}

In this way, with the treatment of the two users, all the possibilities are being considered, both with respect to the type of day and the seasons, of the habitual patterns of uses of the dwellings studied, which can also represent an important range of the majority of residents of homes.

Table 1. Description of buildings

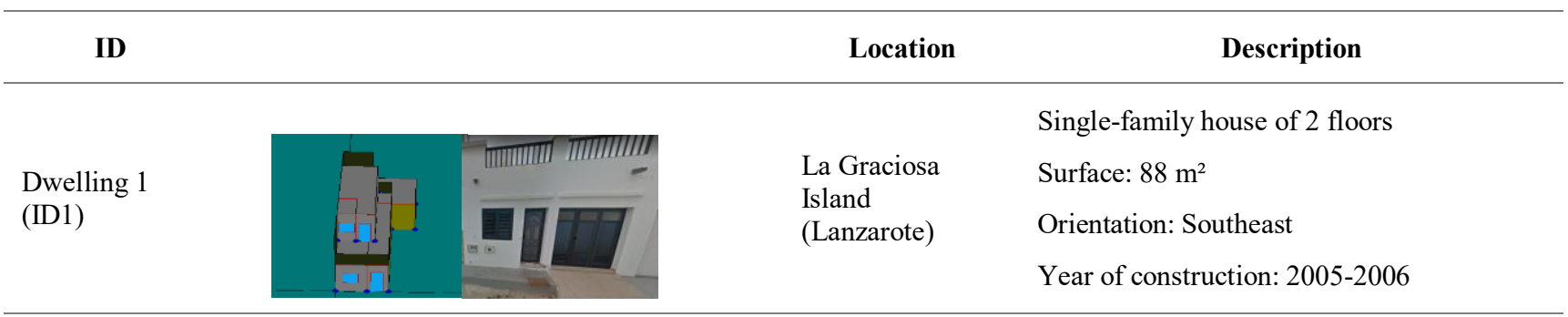

Dwelling 2

(ID2)

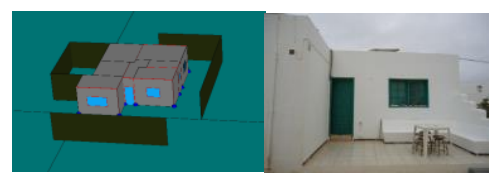

Single-family house of 1 floor

La Graciosa Surface: $60 \mathrm{~m}^{2}$

Island

(Lanzarote)

Year of construction: 2005-2006

Single-family house of 2 floors.

Lozoyuela $\quad$ Surface: $158 \mathrm{~m}^{2}$

(Madrid) Orientation: Northwest

Year of construction: 2004-2005

Single-family house of 2 floors.

Dwelling 4

(ID4)

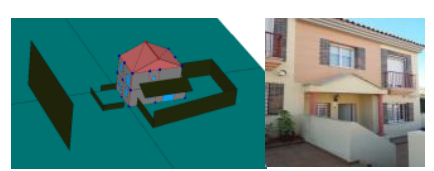

Surface: $182 \mathrm{~m}^{2}$

Alhaurín de la Torre (Málaga)
Orientation: North

Year of construction: 2004-2006

Single-family house of 2 floors.

Espartinas $\quad$ Surface: $230 \mathrm{~m}^{2}$

(Sevilla) South orientation

Year of construction: 1997 


\subsection{Climate}

The buildings already presented are distributed by different climatic zones in Spain, according to the CTE. This is an important aspect that allows to incorporate an alternative to analysis, the possibility of moving the houses between the different zones, without knowing the climatic characteristics of each of them.

Specifically, in this analysis, 5 buildings are considered, three of them located in zone A3 (Canary Islands, could include the area name $\alpha$, discarded, for not giving importance to the study, Malaga), one in area B4 (Seville) and another D3 (Madrid).

In the specific case of the buildings studied, each of them has been simulated in their corresponding locations, but the alternative of moving buildings with similar characteristics by different climatic zones is incorporated, obtaining important results.

\subsection{Electricity Prices}

The electricity sector faces major challenges in the near future, such as changes in the use of electricity, the aging of infrastructure and a greater amount of renewable intermittent electricity generation. To face these challenges, demand side management can play an important role, its combination with electricity rates will be determined throughout the project which can be very influential.

In general, the results are obtained with a current rate in Spain from one of the best-known marketers. Which has two periods, one of valleys hours with a lower price and the other with a higher price, peak hours [8]; It will be called throughout the project as standard.

In the section of influential factors in the results, the influence of applying another rating is analysed, this study includes other existing rates in the electricity market in Spain.

- Tariff 1 (T1): 2 free hours per day, chosen both in winter and summer from 19: 00-20: 00, both included. The remaining hours at $€ 0.140711 / \mathrm{kWh}$.

-Tariff 2 (T2): You choose the 8 hours you want where you apply a reduced rate. The price of the cheap hours at $0.07461 € / \mathrm{kWh}$ and the faces at $0.168531 € / \mathrm{kWh}$. According to the occupancy profiles, for all dwellings the section from 15:00 to 22:00 is chosen as the valley period.

-Tariff 3 (T3): Fixed daily rate of $0.114 € / \mathrm{kWh}$.

-Tariff 4 (T4): Fictitious rate where the price of electricity in the valleys is zero, in advance of the possible unification of all these measures of potential savings with renewable energy.

\subsection{Control HVAC-Strategies -Decision Maker}

For the analysis of the potential of intelligent control of the use of air conditioning and night ventilation in a home, an optimization process has been implemented that analyses all the possible strategies at the beginning of each night and chooses the best one for the operation of that day.

On the one hand, the optimization process requires the following additional parameters:

- Night ventilation: flow extracted from the houses and consumption of the extractors.

- Tariff: price of electricity in the peak and valley hours.

- Stations: months of heating and cooling, as well as setpoint temperatures considered by the user.

- COP of the conditioning system, a COP $=2$ has been used in all cases.

- Start time of the peak period, according to the type of tariff.

On the other hand, the hourly occupancy values must be indicated, which will determine the hours of operation of the air conditioning equipment during the year under study. Finally, it will be indicated that hours of the day correspond to valley / peak hours for electricity prices.

Once all the input data have been entered, all the combinations that you wish to simulate are defined in terms of the hours of night ventilation in summer (compared to the hours before 7 o'clock in the morning), hours of preheating / precooling (with respect to the start time of the peak period), and preheating / precooling setpoint temperatures. In the following section, more information about them is detailed.

The algorithm of the simulation is synthesized in the following scheme, Figure 2, in a general way it is necessary to know as starting data the temperatures in free oscillation (without air conditioning equipment), the demands of air conditioning, both obtained via simulation, the knowledge of the electrical rating to apply and the schedules and slogans of conditioning. All this information is obtained on an hourly basis, it allows knowing for each day, which is the option whose cost is minimal.

Below are the measures carried out in the study of the energy / economic impact of the different homes.

First of all, preheating and precooling strategies are presented, where decisions regarding hours of operation and setpoint temperatures of these will be made. Both alternatives are considered as start-up of the air conditioning equipment a few hours before set occupancy hours.

Table 4. Preheating and Precooling strategies.

\begin{tabular}{|c|c|c|}
\hline \multirow{4}{*}{$\begin{array}{c}\text { PREHEATING/ } \\
\text { PRECOOLING }\end{array}$} & $\begin{array}{c}\text { SET POINT } \\
\text { TEMPERATURES } \\
\left({ }^{\circ} \mathbf{C}\right)\end{array}$ & $\begin{array}{c}\text { No. OF } \\
\text { HOURS }\end{array}$ \\
\cline { 2 - 3 } & 20 & $0 / 1 / 2 / 3$ \\
\cline { 2 - 3 } & 21 & $0 / 1 / 2 / 3$ \\
\cline { 2 - 3 } & 22 & $0 / 1 / 2 / 3$ \\
\cline { 2 - 3 } & 23 & $0 / 1 / 2 / 3$ \\
\cline { 2 - 3 } & 24 & $0 / 1 / 2 / 3$ \\
\hline
\end{tabular}

In relation night ventilation, the number of hours is taken into account, compared to 7 in the morning, time at which the user starts with his usual operating period.

\footnotetext{
* Corresponding author: maricarpavon@
} 
Table 5. Night Ventilation strategies.

\begin{tabular}{|c|c|}
\hline \multirow{4}{*}{\begin{tabular}{c|c|} 
No. OF \\
NOURS
\end{tabular}} \\
\cline { 2 - 2 } VENTILATION & 0 \\
\cline { 2 - 2 } & 1 \\
\cline { 2 - 2 } & 2 \\
\cline { 2 - 2 } & 3 \\
\cline { 2 - 2 } & 4 \\
\cline { 2 - 2 } & 5 \\
\cline { 2 - 2 } & 6 \\
\hline
\end{tabular}

With these alternatives, 192 possibilities are shuffled, range expandable according to the case of the analysis, even so an important range of cases is composed, which allows to obtain conclusive results.

\subsection{Summary}

In general, the results obtained sweep a catalog, which shows all the following cases (Without taking into account, the cases of extra analysis of influential factors), in addition to the 192 different possibilities of selection of strategies, within that possible combinations we have 20 different cases. All combinations shown in figure 3 .

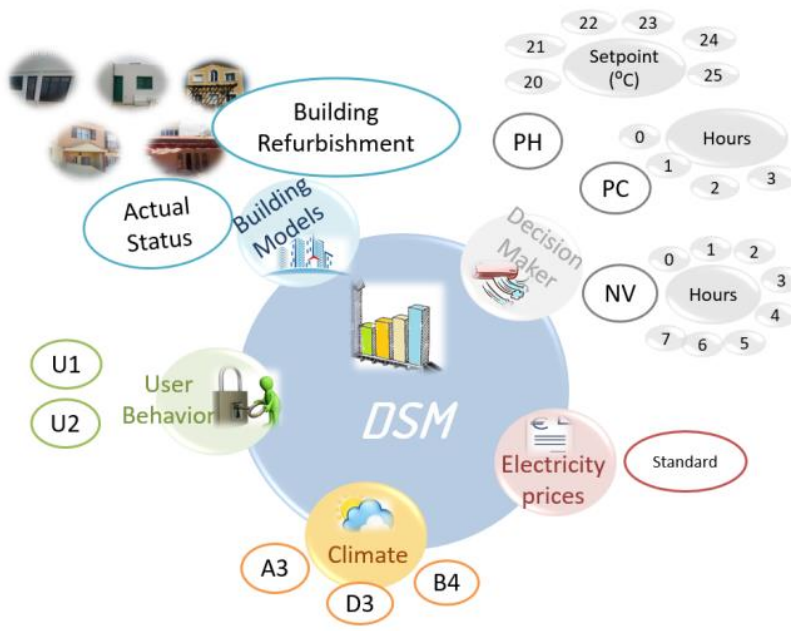

Fig. 3. Summary of cases

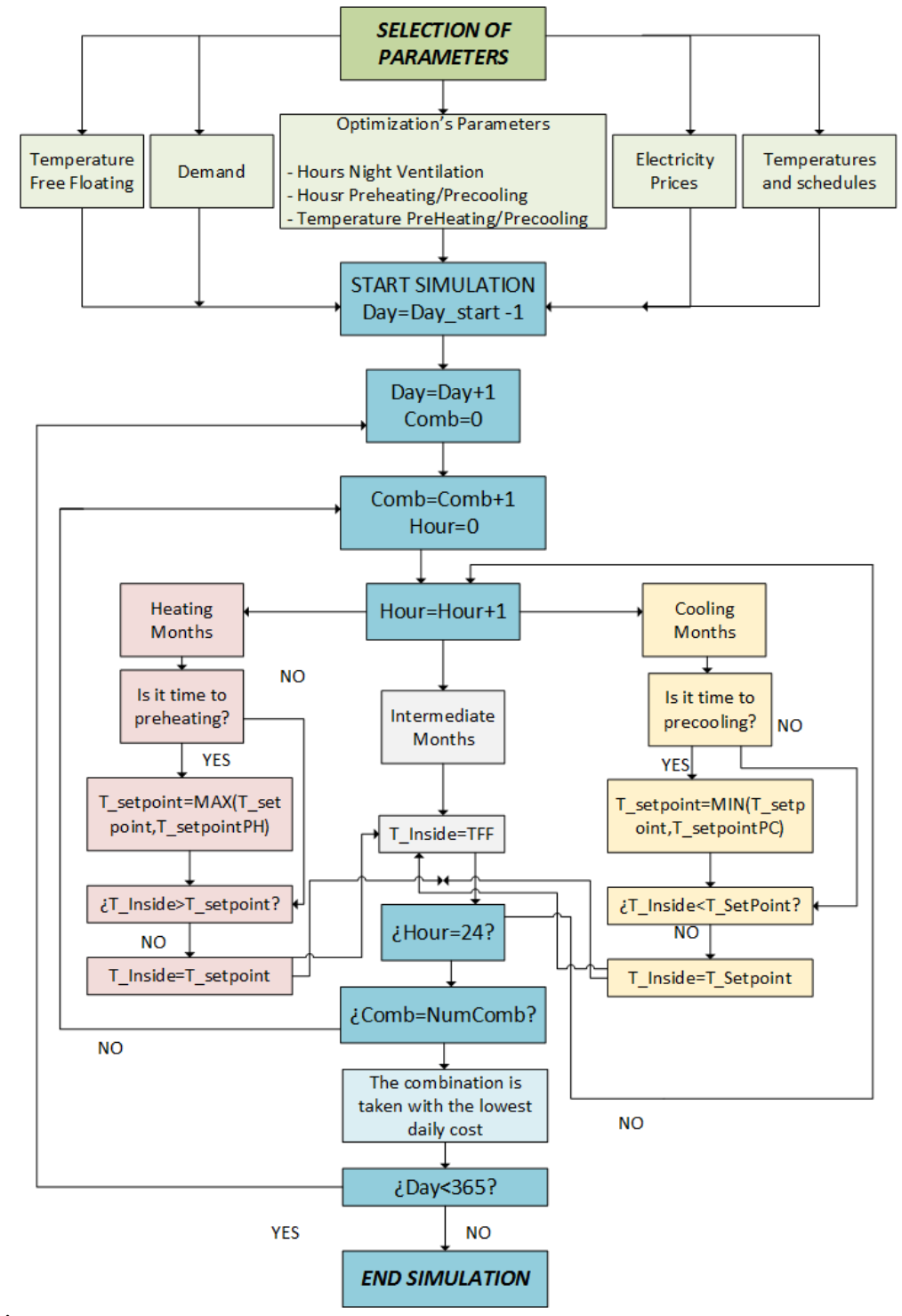

Fig. 2. Algorithm Simulation 


\section{RESULTS}

\subsection{General description of the results}

The objective of this point is to analyze the economic savings on the sample of buildings, which allows establishing a knowledge base linked to the interest that these techniques can arouse.

The results obtained for each building are presented below, with all the alternatives proposed, Table 6, and the influential factors of these results are analyzed.

Table 6. Savings percentages (\%), General Results

\begin{tabular}{|c|c|c|c|c|c|c|}
\hline \multicolumn{7}{|c|}{ Heating Results } \\
\hline \multirow{2}{*}{ BUILDING } & USER & ID & ID & ID & ID & ID \\
& & 1 & 2 & 3 & 4 & 5 \\
\hline \multirow{2}{*}{ Actual } & U1 & 0 & 0 & 3 & 3 & 2 \\
\cline { 2 - 8 } & U2 & 0 & 0 & 0 & 1 & 0 \\
\hline \multirow{2}{*}{ Refurbishment } & U1 & 1 & 0 & 1 & 2 & 7 \\
\cline { 2 - 8 } & U2 & 0 & 0 & 0 & 2 & 10 \\
\hline \multirow{2}{*}{ Cooling results } \\
\hline \multirow{2}{*}{ Actual } & USER & ID & ID & ID & ID & ID \\
& U1 & 2 & 1 & 4 & 9 & 3 \\
\cline { 2 - 8 } Refurbishment & U2 & 5 & 3 & 9 & 14 & 8 \\
\cline { 2 - 8 } & U1 & 14 & 2 & 8 & 25 & 8 \\
\cline { 2 - 7 } & U2 & 19 & 8 & 14 & 27 & 14 \\
\hline
\end{tabular}

\subsection{Influencing Factors}

\subsubsection{User}

Throughout the document, it has been checked how important the user is in making decisions. The key factor of the different users is the period of stop existing between the valley and peak period, as previously stated. This period constitutes the losses of the thermal storage used.

Finally, a complementary analysis has been carried out for one of the dwellings, assuming an optimal user of the application of the strategies. This optimal user eliminates the stop period from 12: $00 \mathrm{~h}$, which ends the rate of hour valleys, until 5:00 PM, which started user 1 . This new user, every day has a conditioning schedule of 13: 00 hours until 23:00, without forgetting the two hours of start in the morning of 7-8.

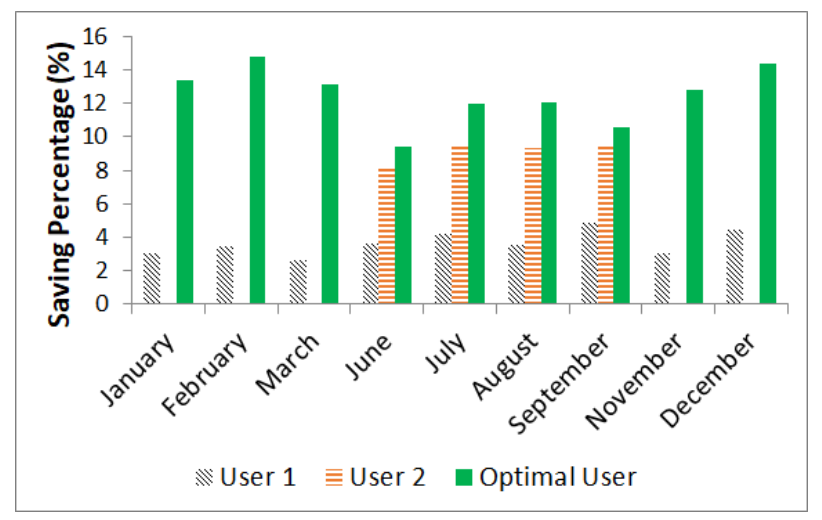

Fig. 4. User influence. Building 3.

The changes are really considerable. Therefore, a variable of basic judgment to consider these measures interesting or very interesting is how housing spaces are conditioned. If the conditioning is continuous, or the price is zero (renewable energy), these measures are very interesting.

\subsubsection{Building}

Next, the influence of improving housing is counteracted to counteract the energy losses during the stop period between valley and peak.

In general, these same results are presented, but aggregated for all households, in the refrigeration station, making sure that this station has not been penalized with the improvement of the building envelope, one of the measures taken for the rehabilitation.

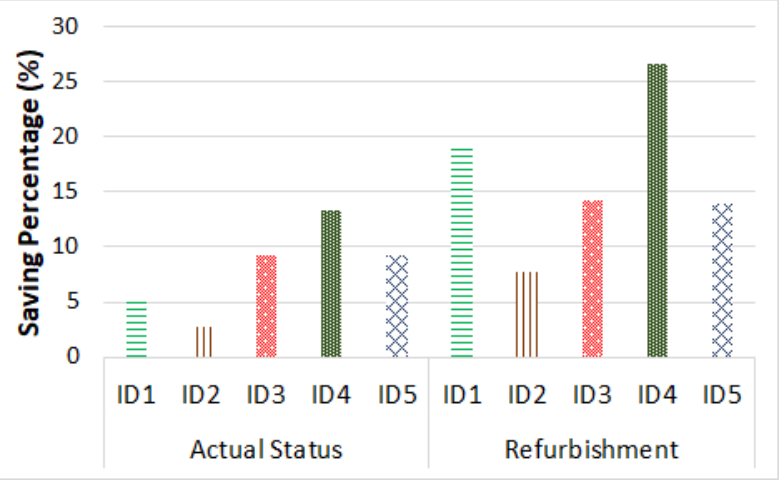

Fig. 5. Building influence.

In all homes there is greater savings in improved buildings compared to their current situation.

\subsubsection{Periods of analysis for decision making}

All the previous results have been chosen with an analysis period of 3 days, after performing various tests with a variable time horizon, the following conclusions are obtained in the specific case of building 3, but that can be extended for all others.

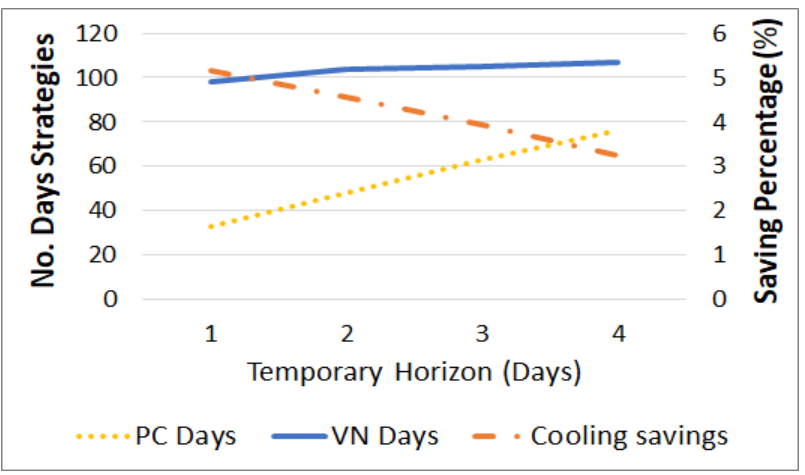

Fig. 6. Periods of analysis for decision making.

In general, as the time horizon increases, the number of days that strategies take increases; however, the potential for saving compared to the base case is reduced, without applying any strategies. A time horizon

\footnotetext{
* Corresponding author: maricarpavon $@$ hotmail.com
} 
of 3 days has been taken, as a midpoint between the number of relevant strategies and the savings potential, observing in the latter that there are no large differences in the analysis interval either.

\subsubsection{Electricity pricing}

Finally, the influence of applying another rating is analyzed, including in this study other existing tariffs in the Spanish electricity market, presented in the upper section of Tarification.

Below are the results obtained for the case of Building 3, with all rates. (Table 7). Generally speaking, it is observed that pricing is an influential element, both in the decision making of the different alternatives and in the potential for economic savings. Distinguishing two types of rates mainly, one of them where the number of strategies increases and therefore saving, others where greater savings are achieved without increasing the number of decisions, simply by the rates.

Table 7. Electricity pricing influence

\begin{tabular}{|c|c|c|c|c|c|c|}
\hline & \multicolumn{6}{|c|}{ Tariffs } \\
\hline \multirow{6}{*}{$\begin{array}{l}\text { Results } \\
\text { User } 1\end{array}$} & & $\begin{array}{l}\text { Stan } \\
\text { dard }\end{array}$ & $\mathrm{T} 1$ & $\mathrm{~T} 2$ & $\mathrm{~T} 3$ & $\mathrm{~T} 4$ \\
\hline & $\begin{array}{c}\text { Heating } \\
\text { Savings (\%) }\end{array}$ & 3 & 4 & 9 & 10 & 69 \\
\hline & $\begin{array}{c}\text { Cooling } \\
\text { Savings (\%) }\end{array}$ & 4 & 47 & 38 & 24 & 54 \\
\hline & No. PH Days & 65 & 0 & 150 & 0 & 150 \\
\hline & No. PC Days & 63 & 121 & 76 & 0 & 121 \\
\hline & No. VN Days & 105 & 46 & 52 & 59 & 115 \\
\hline
\end{tabular}

\section{CONCLUSIONS}

The study presents intermediate results and conclusions in each of the studies carried out. However, it is worth mentioning:

- The economic savings linked to the demand management strategies are strongly dependent on the user's behavior (first place) and the constructive quality of the building (losses of stored energy).

- Housing pricing is key to these strategies and how they are distributed throughout the day

- It is implicit in the results that having a renewable production of electricity can maximize economic savings. A relevant future job is the use of buildings as thermal storage of the surplus of the photovoltaic not consumed in the house.

- Another point of enormous interest is to combine these measures with electrical storage and with the possible arbitrage linked to renewable production.

Finally, highlight the previous conclusions: Project advances linked to the algorithm and its exploitation in the definition of intelligent operation strategies, can be complemented with an optimal design algorithm for photovoltaic systems with or without accumulation, and possible strategies related to employment of the buildings as substitutes / complements of the lithium batteries for surpluses or depending on the prices of the arbitration.

\section{ACKNOWLEDGMENT}

The authors would like to take this opportunity to thank the DACAR project "Zero-Energy Balance Districts Through Algorithms of Adaptive Comfort and Optimal Management of Energy Networks" (BIA2016-77431C2-2-R) funded by Ministry of Economy and Competitiveness (Government of Spain) and European Regional Development's funds (ERDF) for its partial support. The authors also thank the University of Seville for its financial support through the US Research Plan VI (VPPI-US).

\section{REFERENCES}

1. IDAE, Plan de Acción de Ahorro y Eficiencia Energética, (2011-2012)

2. C. Gellings. Proc. IEE. The concept of demand-sidemanagement for electricts utilities, 1468-1470 (1985)

3. Ministerio. Herramienta Unificada LIDERCALENER (HULC)

4. R. Judkoff, J. Neymark. Natl Renew Energy Lab. International Energy Agency building energy simulation test (BESTEST) and diagnostic method, 296 (1995)

5. Código Técnico de la Edificación (CTE). https://www.codigotecnico.org/images/stories/pdf/a horroEnergia/DBHE.pdf

6. M. Delmas, M. Fischlein, M.Asensio. Energy Policy. Information strategies and energy conservation behavior: A meta-analysis of experimental studies form 1975 to 2012, 729-739 (2013)

7. Podgornik, B. Socic, B.Blazic. J. Clena Prod. Effects of customized consumption feedback on energy efficient behaviour in low-income households, 130, 25-34 (2015)

8. Endesa.https://www.endesaclientes.com/blog/discri minacion-horaria 